\title{
Planejamento e gestão de resíduos sólidos: um desafio aos municípios
}

\section{Planning and solid waste management: a challenge to municipalities}

\begin{abstract}
José Laécio de Moraes ${ }^{a}$
${ }^{a}$ Mestre e doutorando em Geografia/UNESP Campus Rio Claro-SP; Professor Substituto do Departamento de Ciências Biológicas da Universidade Regional do Cariri (URCA); Consultor Ambiental da Superintendência Estadual do Meio Ambiente do Ceará (SEMACE) e do Instituto Brasileiro do Meio Ambiente e dos Recursos Naturais Renováveis (IBAMA). E-mail: laeciomoral@hotmail.com
\end{abstract}

Recebido em: 26/10/2016 I Aceito em: 02/12/2016 


\title{
RESUMO
}

O planejamento através dos planos de gestão de resíduos sólidos é um dos importantes instrumentos da Lei no 12.305/2010 - Política Nacional de Resíduos Sólidos (PNRS) - e surge como uma das possíveis soluções para os problemas enfrentados pelos gestores municipais da área de resíduos sólidos. O presente trabalho visa analisar a importância do planejamento para o setor de resíduos e os resultados da PNRSno que diz respeito à elaboração dos planos municipais de resíduos sólidos, ação esta que teve seu prazo encerrado em 2 de agosto de 2012, tendo aqueles municípios descumpridores do prazo a principal consequência de estar impedidos de receber repasses de recursos estaduais e federal para o setor de resíduos sólidos. O procedimento metodológico utilizado como base neste trabalho consistiu na utilização de pesquisa bibliográfica e aplicação do método qualitativo, através da coleta de informações e entrevistas efetuadas a gestores municipais (prefeitos, secretários e coordenadores de meio ambiente) da região Centro-Sul do estado do Ceará. Os resultados apontam que todos os 13 gestores municipais da região estudada alegam não possuir recursos financeiros para a elaboração desses planos, 11 municípios não dispõem de equipes suficientemente capacitadas para a realização de tais,e todos afirmam já possuírem planos elaborados, porém não atendem ao exigidos pela PNRS, além de enfrentar limitações técnicas para a implementação dos mesmos. Nesse sentido, consideramos que a elaboração dos planos municipais de resíduos sólidos tem sido um desafio aos gestores municipais, uma vez que demandam conhecimento técnico especializado para elaboração, implantação e implementação.

Palavras-chave: Planejamento. Resíduos sólidos. Gestão de resíduos.

\begin{abstract}
Planning through the solid waste management plans is one of the important instruments of Law № 12.305 / 2010 - National Policy on Solid Waste (PNRS) - and emerges as one of the possible solutions to the problems faced by municipal managers in the area of solid waste. This study aims to analyze the importance of planning for the waste sector and PNRS results regarding the elaboration of municipal plans of solid waste, action that had its term ended August 2, 2012, and those municipalities that failed to meet the main consequence of being unable to receive transfers from state and federal funds for the solid waste sector. The methodological procedure used as the basis of this work was the use of bibliographic research and application of qualitative method, through the collection of information and interviews made to municipal managers (mayors, secretaries and environmental engineers) of the state of Ceará South-Central region. The results show that all 13 municipal managers of the studied region claim not to have financial resources to draw up such plans, 11 municipalities do not have enough teamstrained to conduct such, all claim to already have elaborate plans, but do not meet the required by PNRS, besides facing technical constraints to implementation. In this sense, we believe that the development of municipal plans of solid waste has been a challenge to municipal managers, as demand technical expertise for the development, deployment and implementation.
\end{abstract}

Keywords: Planning. Solid waste. Waste management 


\section{INTRODUÇÃO}

O conceito de planejamento voltado às políticas públicas apareceu e foi incorporado pelo poder público há cerca de um século, com o objetivo de prever os resultados a serem obtidos, principalmente em projetos de planejamento urbano, através de documentos chamados planos. Desde esse tempo, muitas cidades do Brasil já padeciam de uma série de problemas de saneamento básico, entre eles, os relativos à coleta e disposição final de resíduos, como os ocorridos na cidade de Rio de Janeiro, responsáveis por graves distúrbios à saúde pública.

Primeiramente, de forma concreta, ele surgiu como planejamento espacial visando o ordenamento territorial das cidades na segunda metade do século XIX e início do século XX na Inglaterra. Difundiu-se o conceito de cidade jardim (HOWARD, 1996), que consistia na idealização de uma cidade para que se tornasse a mais amena possível, distribuindo espacialmente suas funções. Sendo, assim, uma resposta ao crescimento desordenado das cidades europeias naquela época, ocasionando poluição nas suas diversas formas, engarrafamento veicular e reduzida qualidade de vida aos cidadãos. Este conceito teve um impacto significativo na área de urbanismo do século XX, com o surgimento de várias cidades-jardim em diversas partes do mundo (Brasília teve sua concepção influenciada a partir da evolução desse conceito). Assim, nesse sentido, o planejamento, que já incluía itens relativos a salubridade pública, era tratado como uma função estritamente técnica do urbanista ou arquiteto, que seria uma espécie de visionário, imagem que resiste até os dias atuais.

Com a criação da União das Repúblicas Socialistas Soviéticas (URSS) no fim da década de 1910, surge uma outra vertente de planejamento: o planejamento econômico centralizado. Nesse modelo o Estado detinha total controle sobre todos os tipos de recursos e os disseminaria de acordo com os planos e metas apontados por políticos ou burocratas. A ausência de democracia na determinação do plano era clara. Nesse caso observa-se o padrão controlador do planejamento, um pouco da ideia que ainda permanece no Brasil, onde o planejamento tem função controladora e é dominado por políticos e burocratas, além do caráter governamental e econômico (OLIVEIRA, 2006). 
Carneiro (2016) relata que entre as décadas de 1920 e 1950 a URSS promoveu diversas mudanças que possibilitaram que os soviéticos suportassem os efeitos das crises econômicas do período entre guerras, como a própria escalada da Segunda Guerra Mundial, além de transformar a URSS na segunda potência industrial do mundo, em pouco mais de duas décadas. Para isso, utilizou-se da burocratização e a adoção de múltiplas medidas coercitivas, que afetaram mais de três milhões de cidadãos.

Esta modernização da realidade soviética foi incentivada através de um intenso trabalho de planejamento da economia, que resultou nos Planos Quinquenais Nacionais, conhecido como primeiro modelo de planificação da economia, pela qual a produção, consumo e distribuição da produção das indústrias, e mesmo da agricultura, eram intensamente planejados por economistas e estatísticos rigorosamente controlados por políticos. Sendo, esses planos globais desagregados em sub-planos anuais e específicos por setores da economia. Buscavam uma projeção ao futuro, alicerçada no pleno emprego dos meios de produção, muito além do que poderia ser esperado, dadas as deficiências tecnológicas e humanas apresentadas na época pela sociedade russa em geral (CARNEIRO, 2016).

Em outra perspectiva, Oliveira (2006) destaca que entre as décadas de 1930 e 1950, a vertente espacial-urbanística do planejamento nos Estados Unidos e Europa se desenvolveu de forma mais abrangente, buscando conglomerar as áreas social e econômica do planejamento, provavelmente como resultado da influência do exemplo soviético do planejamento, onde o regime político orientador se expandia pelos países do Leste europeu e Ásia. Nesse momento, além das ideias de forte intervenção estatal nas economias do mundo capitalista manifestaram significativa ascensão, teve início o planejamento e se estabeleceram políticas de desenvolvimento regional, que resultaram na criação das conhecidas agências orientadas ao desenvolvimento, como Cassa per il Mezzogiorno na Itália, Tennessee Valley Authority (TVA) nos EUA e Superintendência do Desenvolvimento do Nordeste (Sudene) e Superintendência do Desenvolvimento da Amazônia (Sudam) no Brasil (OLIVEIRA, 2006). Ainda com a ideia de planejamento como motor para desenvolver planos para controlar o futuro, com importante papel governamental nas decisões do planejamento. 
Várias mudanças no conceito de planejamento seguiram a partir da década de 1970 e em diante. O planejamento deixava de ser visto apenas como um instrumento técnico, e necessitaria ser um instrumento político, de maneira a harmonizar e articular os múltiplos interesses envolvidos no processo de intervenção de políticas públicas. O planejador deveria ser o mediador dos interesses da sociedade no processo, e o resultado final deveria ser tomado preferencialmente em consenso dos entes envolvidos (SUSSKIND; KRUIKSHANK, 1987).

Nesse sentido, surge o conceito de planejamento colaborativo, que buscava a confiança e credibilidade nas decisões do planejamento de políticas públicas (HEALEY, 1997). O planejamento, nesses moldes, se consolidou como um processo que passa a depender da maneira como ocorrem as relações de confiança entre as partes envolvidas e influenciadas pelas decisões. A ideia de se aprender através das interações nos processos de decisão passou a ser considerada extremamente importante para pensar-se no planejamento (OLIVEIRA, 2006). Nessa ótica, o processo de planejamento é também um processo que inclui a etapa da tomada de decisões políticas, as que dependem de informações concisas e atualizadas, de transparência, temperança, ética, concordância de visões diferentes em função da diversidade profissional dos tomadores de decisão e do anseio de negociar e buscar soluções de forma conjunta, para que sejam oportunas para toda a sociedade e sobretudo para as partes envolvidas.

No Brasil, o planejamento é extremamente ligado à elaboração de planos e ao controle estatal desses planos. A história brasileira nos permite verificar a existência de uma grande quantidade de planos que já foram e seguem sendo elaborados; como exemplo pode-se citar os planos: trienais, decenais, plurianuais, nacionais, regionais, municipais, econômicos, de desenvolvimento, diretores, etc. pode-se afirmar que temos uma boa cultura prática para elaborar planos, com a ideia de prever e organizar ações futuras, como se isso fosse possível de maneira lógica e previsível.

Nessa perspectiva, decidimos avaliar a importância do planejamento ambiental na área de resíduos sólidos através dos planos municipais de gestão de resíduos, um dos instrumentos da Lei Federal no 12.305/2010 - Política Nacional de Resíduos Sólidos (PNRS), legislação elaborada após um debate de quase vinte anos que visa solucionar os problemas enfrentados pelos gestores municipais na 
área de resíduos sólidos.Analisar os resultados da PNRS no que diz respeito à elaboração dos planos municipais de resíduos sólidos, ação esta que teve seu prazo encerrado em 2 de agosto de 2012, tendo aqueles municípios descumpridores do prazo a principal consequência de estar impedidos de receber repasses de recursos estaduais e federal para o setor de resíduos sólidos, é também parte do nosso objetivo. Para este estudo utilizamos como procedimento metodológico a pesquisa bibliográfica e aplicação do método qualitativo, através da coleta de informações e entrevistas efetuadas a gestores municipais (prefeitos, secretários e coordenadores de meio ambiente) da região Centro-Sul do estado do Ceará, composta por 13 municípios (Acopiara, Baixio, Cariús, Catarina, Cedro, Icó, Iguatu, Ipaumirim, Jucás, Orós, Quixelô, Saboeiro e Umari) que juntos totalizam uma área absoluta de $11.581,536 \mathrm{~km}^{2}$ e apresentam uma população de 388.364 habitantes.

\section{A PARTICIPAÇÃO SOCIAL NO PLANEJAMENTO}

Um ponto complexo na elaboração de planejamentos, planos e projetos de qualidade do Brasil é que muitos deles acabam se tornando mais caros, maiores e complicados do que deveriam ser. Como resultados têm-se dificuldades e obstáculos ou até inaplicabilidade desses dentro do complexo aparelho governamental existente no Brasil; como exemplo podem ser citados a rodovia Transamazônica e o projeto Polonoroeste. Em síntese, infelizmente, muitos dessas modalidades de planejamentos fracassaram porque não houve compatibilidade entre a elaboração e a implementação do que foi anteriormente planejado.

Vários projetos falham por não terem uma implementação estabelecida, por se tornarem muito burocráticos, ou ainda por não considerarem importante a participação e o diálogo com as esferas incluídas nele. Uma vez que existe uma multiplicidade de intuitos, disputas e embates que entusiasmam, significativamente, o processo político e a efetivação dos projetos, e que precisam ser identificados e considerados. (OLIVEIRA, 2006)

Nesse ponto de vista, Giron (2012) defende que não há um padrão de política que consiga separar as fases de planejamento e implementação, uma vez que os profissionais ou cidadãos envolvidos no processo, também são responsáveis (em última análise), pela elaboração e efetivação das mesmas. Ou seja, as políticas 
públicas estão sempre em processo de construção, pois são fruto de diversas leituras de mundo, realizadas pelos distintos atores sociais participantes, os quais estão inseridos em diferentes realidades socioeconômicas e culturais. Assim, as políticas públicas não podem, dessa forma, ser analisadas somente como procedimentos de produção e implementação (alguma pessoa que pensa e outra que executa), sendo que a criação e a concretização das políticas públicas são processos que vão sucedendo-se e que sofrem modificações e inferências dos diferentes participantes envolvidos.

A questão da participação comunitária tem implicado não apenas a imposição de um caráter necessariamente democrático ao planejamento, mas também uma mudança na maneira de se trabalhar. Ampliam-se não apenas os agentes envolvidos no processo de planejamento, mas, igualmente, os temas de interesse tratados. (REZENDE; ULTRAMARI, 2007)

Esse modo de observar a construção de políticas públicas possibilita uma reflexão sobre como os diferentes atores políticos (população em geral e gestores públicos) cumprem um papel ativo no processo de planejamento, considerando que as políticas sempre serão elaboradas e entendidas de acordo com a história, experiência, valores e intenções das pessoas envolvidas no contexto, pois o entendimento é um tema de disputa, relacionando-se com interesses diversos, cabendo ao poder público considerar o maior número de variáveis que possam influenciar no planejamento, a fim de torná-lo o mais aplicável possível (GIRON, 2012).

\section{PLANEJAMENTO NA GESTÃO DE RESÍDUOS SÓLIDOS}

A partir do processo de redemocratização do Brasil e da promulgação da Constituição de 1988, sobreveio uma reorganização institucional e legislativa que gerou uma longa fase de mudanças significativas em favor do meio ambiente e da qualidade, de vida nas cidades. Com a promulgação do Estatuto da Cidade, aprovado em 2001, que instituiu novos marcos regulatórios; e preceitos de gestão urbana, como as leis de saneamento básico, em geral, e de resíduos sólidos, em particular. Estes dois marcos regulatórios, caso implementados e operacionalizados corretamente, poderão num horizonte razoável de tempo, realinhar a capacidade de 
administrar os serviços públicos urbanos de forma mais eficiente, congregando e definindo responsabilidades de maneira compartilhada com toda a sociedade, os mais diversos setores da economia e o poder público (BRASIL, 2011).

Nessa perspectiva de redemocratização, Brasil (2011) reforça o pensamento ao afirmar que o poder público passa a não ser mais o único ente responsável por "cuidar" dos serviços urbanos, pois muitas das responsabilidades passaram a ser compartilhadas por outros setores, buscando soluções para os problemas ambientais causados pela grande concentração de atividades nos ambientes urbanos, com destaque para a ausência saneamento básico e carência na prestação dos serviços de manejo, tratamento e disposição final dos resíduos sólidos urbanos.

Muitos desses problemas se devem à inexistência de pessoal especializado com capacidade para gerir o setor e às fragilidades na habilidade de gestão em diversas esferas de poder no país. As deficiências anteriormente apresentadas resultam em um cenário contraproducente, onde poucos municípios dispõem das condições necessárias para realizar uma gestão adequada dos resíduos sólidos, de forma a garantir que os serviços sejam sustentáveis e que as novas disposições legais sejam implantadas de forma efetiva a racionalidade na aplicação dos recursos técnicos, humanos e financeiros. Para isso, são necessários esforços na aplicação de políticas de planejamento que visem mitigar tais fragilidades presentes na gestão de resíduos sólidos.

Na experiência internacional, foi com essa preocupação que Portugal adotou como modelo de planejamento o Plano Estratégico de Resíduos Sólidos Urbanos (PERSU), instrumento utilizado na gestão dos resíduos sólidos de suas cidades. Essa estratégia define um conjunto de eixos de atuação, através de mecanismos de prevenção, sensibilização/motivação da sociedade em geral, qualificação de servidores da área de resíduos, otimização do aproveitamento dos resíduos e utilização de sistemas de informação como base da gestão de resíduos, uma vez que possibilita o monitoramento da eficiência dos serviços prestados.

As decisões no âmbito da gestão dos resíduos sólidos, na visão da ABLP/SELUR (2014) devem ser baseadas nos planos de gestão de resíduos sólidos, os quais devem ser utilizados como um instrumento efetivo de planejamento, levando em consideração a realidade e as características especificas do município em questão, uma vez que a ausência de diretrizes dificulta a tomada 
de decisões sobre qual o melhor modelo a ser adotado e quais as ações previstas a médio e longo prazos em cada caso.

A falta do prévio e adequado planejamento técnico-econômico tem dificultado a otimização de resultados e tornado a gestão de resíduos cada vez mais onerosa aos municípios, aliado a essas falhas vem o agravante da inexistência de regulação e controle social no setor, fato que inviabilizam a identificação dos entraves para o sucesso da gestão.

Quando há inexistência de planos de gestão integrada de resíduos sólidos, a pouca qualidade e confiabilidade das informações e dos registros disponíveis para a gestão dos resíduos também dificulta muito o planejamento, por exemplo, no dimensionamento e na logística da frequência para os serviços de limpeza urbana, como a varrição de ruas e calçadas, a pintura de meio fios, o cumprimento de horário de coleta de resíduos, dentre outras (ABLP/SELUR, 2014)

Os fundamentos e as premissas para elaborar o planejamento e os planos municipais propostos precisam de requisitos e devem contar, necessariamente de condições a serem cumpridas, como a disponibilidade de informações, conhecimentos específicos do município e de sua estrutura de gestão, possíveis ações estratégicas, postura estratégica dos gestores locais, empreendedorismo e desejo de inovação (REZENDE; ULTRAMARI, 2007)

Um exemplo exitoso no planejamento da gestão dos resíduos sólidos é o município de Joinville, no estado de Santa Catarina, sendo um dos primeiros municípios a aprovar um plano municipal de resíduos sólidos, já dispondo de um Plano Municipal de Saneamento Básico desde 2003, modelo esse que poderia ser plenamente seguido pelos demais municípios brasileiros, respeitadas as realidades de cada localidade.

Nessa perspectiva, entendemos que o planejamento é fundamental para o sucesso na implantação e operacionalização de políticas públicas, em especial na área da gestão de resíduos sólidos.

\section{CARACTERIZAÇÃO DA ÁREA DE ESTUDO}

Para este estudo definimos como recorte espacial a região Centro-Sul do Estado do Ceará - uma das 14 Regiões de Planejamento definidas pelo Governo 
Estadual. A região é composta por 13 municípios, já citados anteriormente, e está constituída por solos condicionados pela litologia, predominando rochas cristalinas, como gnaisses, migmatitos e granitos, os solos assumem tonalidades claras e composição arenosa e ou areno-argilosa. Já os solos derivados de filitos e micaxistos são argilosos, com coloração avermelhada, apresentando óxido de ferro e cascalhos de granulometria variada, oriundos da desagregação de veios de quartzo. Nos aluviões, principalmente nos sedimentos contendo argila, bem como sobre rochas básicas e ultrabásicas, o solo assume coloração cinza e marrom escuro, respectivamente, e conteúdo altamente argiloso, característica que contribui para baixa permeabilidade de solo e consequentemente apresenta característica ideal para implantação de estruturas de tratamento de resíduos sólidos, com baixos riscos de contaminação de lençol freático. A (BENDELAK, 2004).

Quanto às feições físicas, a região tem altitudes médias que variam de 153,4m no município de Icó a 520m de altitude em Catarina. Um fato notório a ser considerado é que embora haja certa diferença de altitudes entre os diversos municípios, esta não influência na dinâmica de gestão de seus resíduos sólidos, pois em todos os territórios municipais existem condições de relevo favoráveis à instalação de equipamentos de tratamento e disposição final de resíduos sólidos.

Nessa região as principais unidades geomorfológicas, importantes de considerar, uma vez que se relacionam com a construção de aterros sanitários, compreendem a depressão sertaneja submetida em parte ao processo de sedimentação, sendo os sítios de valor paisagístico formados por parte dos açudes de Orós, Lima Campos e Trussu e o Vale do Jaguaribe drenado pelos rios Salgado, Jaguaribe e Trussu. A drenagem dominante é do tipo dendrítica e muito densa em função da impermeabilidade dos terrenos cristalinos. (BENDELAK, 2004).

Localizada na região fisiográfica do sertão nordestino, a área possui como clima dominante o semi-árido, com duas estações bem definidas: uma chuvosa com precipitações pluviométricas de janeiro a maio (com máxima nos meses de marco e abril) e a outra seca no restante do ano. Normalmente as chuvas são irregulares, principalmente nas regiões mais planas. As precipitações médias anuais oscilam em torno de $800 \mathrm{~mm}$, sendo que nas zonas de elevada altitude superam os $1.000 \mathrm{~mm}$ anuais. A temperatura na região estudada oscila entre $20^{\circ}$ e $38^{\circ} \mathrm{C}$, com médias entre $27^{\circ}$ e $28^{\circ} \mathrm{C}$. O vento na região é predominantemente leste-oeste, atingindo 
maior velocidade no mês de outubro e menor no mês de abril (BENDELAK, 2004). Incluímos essas variáveis por apresentar relações com o transporte e disposição final dos resíduos sólidos.

Como resultado das características anteriormente elencadas, temos uma cobertura vegetal com predominância de vegetação de caatinga, típica do semi-árido nordestino, composta principalmente de espécies vegetais herbáceas, como Hyptissauaviolens (L.) point (Bambural) e Hyptissp. (melosa) seguida, em menor proporção, de espécies vegetais de caráter arbustivo e arbóreo, como Aspidosperma pyrifolium Mart (Pereiro) (ALVES, 2008), que corresponde a uma vegetal de reduzida importância florística, contudo devem ser consideradas quando projeta-se a construção de aterros sanitários.

A área estudada é escassa de estudos socioeconômicos, havendo assim pouca disponibilidade de informações, sejam elas atualizadas ou não. Sendo uma região caracterizada pela baixa densidade populacional, com cerca de 33,43 hab $/ \mathrm{km}^{2}$, se comparada com a média do Estado Ceará, que era de 56,76 hab. $/ \mathrm{km}^{2}$ no ano de 2010. A população total estimada para a região, segundo o IBGE (2015) era de 388.364 habitantes, com taxa geométrica de crescimento anual em torno de $1,34 \%$, estando a maior parte da população concentra nos municípios de Iguatu, Icó e Acopiara, consequentemente, estes três municípios são também os maiores produtores de resíduos e apresentam importante influência no planejamento da gestão regionalizada destes resíduos.

A estrutura por setores produtivos é composta, principalmente, pelas indústrias de transformação e extração vegetal (madeira, carvão vegetal e lenha), móveis, de madeira e tubular, dentre outras, já no setor de comércio/serviços são predominantes os alugueis e serviços, construção civil, alimentação e alojamento, reparação de veículos automotores, transporte e armazenagem, atividades imobiliárias, comércio de objetos pessoais e domésticos e outros serviços coletivos, pessoais e sociais.

Embora registre-se constantemente déficit hídrico em algumas áreas durante determinados meses do ano, a região permite a produção de diversas culturas agrícolas como arroz, feijão, milho, banana, goiaba, manga, abacaxi, uva e várias hortaliças. Além disso, destaca-se a criação de bovinos, caprinos, ovinos e aves em confinamento, principais atividades pecuárias propulsoras da economia regional. 


\section{OS PLANOS DE GESTÃo DE RESÍDUOS SÓLIDOS}

O apoio político e compreensão da necessidade de elaborar planos de gestão para resíduos sólidos são cruciais para o adequado planejamento. Se um plano já existir, ele pode ter que ser revisto. Se, por outro lado, o primeiro plano de gestão de resíduos ainda tem de ser concebido, é muito importante que em nível político seja aceita a necessidade de elaborar um plano e alocados recursos suficientes para a sua execução, pois pouco adianta existir um plano, se conjuntamente não existirem os recursos que possibilitem sua efetiva implementação e operacionalziação.

Como ponto de partida o planejamento na área de resíduos sólidos deve incluir uma reflexão sobre as seguintes questões, entre outras:

- Por que elaborar um plano de gestão de resíduos?

- Qual é o escopo do plano de gestão de resíduos?

- Quem estará envolvido na gestão dos resíduos considerados no plano?

- Qual é o prazo para a finalização do plano de gerenciamento?

- Qual é a relação com outros planos já existentes?

- Com que dotação orçamentária se contará?

- Como entrará a participação da sociedade?

A consideração dos questionamentos anteriormente apresentados é fundamental para criação e implementação de planos para gestão resíduos sólidos que sejam capazes de contemplar a realidade dos municípios.

Nesse sentido, ao ponderarmos a importância da elaboração de um plano de gestão dos resíduos sólidos devemos levar em consideração a relevância de fazerse um diagnóstico que indique as fontes de geração, caracteristicas e volumes de resíduos gerados, tipo de coleta e preiodicidade da mesma, transporte e tratamento, e bem como identificar as falhas que o sistema possui, para corrigi-las futuramente.

$\mathrm{O}$ entendimento correto e abrangente sobre o manejo de resíduos torna-se indispensavel, uma vez que, prioridades devem ser difinidas, para a correta e eficiente aplicação do plano proposto, cosiderando, incluive os fatores econômicos envolvidos no processo (custos de manejo dos resíduos, fontes de financiamento da gestão, possibilidade de comercialização dos resíduos para indústria de reciclagem, etc).

Ciência e Sustentabilidade - CeS / Juazeiro do Norte v. 2, n. 2, p. 63-83, jul/dez 2016 
Na maioria dos países as autoridades locais (prefeituras) são responsáveis apenas pela gestão de resíduos urbanos. No entanto, em alguns países as autoridades locais também decidem optar por gerenciar outros tipos de materiais, como os resíduos industriais, podendo também à municipalidade a responsabilidade para gerenciar todos os resíduos, como os da saúde, agricultura, etc.

Os planos de gestão de resíduos devem considerar prazos para a execução das ações e seus resultados esperados, traçando metas para curto, medio e longo prazo. A razão de se estipular uma perspectiva de longo prazo para planos de resíduos consiste em que devem ser consideradas as dificuldades a serem enfrentadas na identificação dos locais adequados para as instalações de tratamento de resíduos ou para definir locais para aterros dentro, ou perto de áreas urbanas, não constituem tarefas faceis de executar, como a escolha do local, avaliação de impactos ambientais e consultas públicas, a fim de obter a permissão para novos locais de tratamento e disposição de resíduos. Finalmente, instalações de tratamento de resíduos demandam grandes investimentos que precisam ser recuperados ao longo de um período mais longo.

De um ponto de vista prático, o horizonte temporal de um plano de resíduos deve também ser longo o suficiente para torná-lo possível de avaliar se as metas estão sendo atingidas. Por conseguinte, não será prático para reavaliar um plano antes de pelo menos três anos, devendo ser refletidas outras variáveis de natureza política, por exemplo, a período entre as eleições locais.

Um outro aspecto relevante está centrado na necessidade do envolvimento das diversas partes interessadas, fundamentalmente a da comunidade em geral, geradora de resíduos. Todos os setores da sociedade têm que participar no processo de planejamento pois se deve procurar assegurar a aceitação da política de resíduos e contribuição de todos para a realização integral dos seus objetivos, considerando os vários níveis da administração e refletindo tradições culturais e organização política.

O processo de planejamento da gestão de resíduos deve incluir uma grande quantidade de atores dos diversos setores, a fim de cobrir todos os aspectos importantes, tornando a discursão inclusiva e participativa.

Durante a fase de diagnóstico, a coleta e o sistema de tratamento de resíduo atualmente empregado devem ser muito bem descritos em termos físicos, 
financeiros e organizacionais. Consequentemente, deve ser analisado o estado do sistema permitindo a verificação se ele atende aos objetivos que já estão definidos, tais como: reciclagem, determinação de fluxos de manejo dos resíduos, ou alcançar certas normas ambientais relacionadas com as estruturass físicas onde se manipulam os resíduos, etc. O diagnóstico é realizado principalmente junto às autoridades administrativas, em cooperação com os vários entes envolvidos na gestão dos resíduos.

Para se realizar o dignóstico adequado, e da forma mais correta possível, é importante a utilização de dados e informações precisas, atualizadas e válidas. Os dados podem ser obtidos através do desenho de um sistema de comunicação com os dados regulares de saída de resíduos de algúm local determinado (ex. estação de transbordo), de ou por levantamentos de dados individuais, primários, na fase de preparação do plano de gestão de resíduos.

É necessário se ter em mente que a coleta de dados, muitas vezes requer um trabalho extenso e demorado porque necessitam séries temporáis longas de coleta de informação, sendo, portanto, aconselhável iniciar com a estruturação e desenvolvimento de sistemas de coleta de dados quanto mais cedo possível para começar com o processo de planejamento.

No início do processo de coleta de informações, pode ser difícil conseguir números confiáveis. Fontes potenciais de dados de resíduos são:

- os produtores de resíduos: esses têm a obrigatoriedade legal de elaborar seus préprios planos de gerenciamento de resíduos, dispondo de dados confiáveis sobre tipo e quantidade de resíduos gerados;

- empresas de coleta e tratamento de resíduos: que podem ser solicitados a relatar regularmente sobre o tipo, quantidade e origem dos resíduos admitidos, o tipo de operação de tratamento de resíduos e o que foi produzido secundariamente (saída). Além disso, informações econômicas podem ser obtidas de outras fontes, como por exemplo os custos de tratamento de resíduos;

- sistemas de coleta de resíduos: que são responsáveis por gestão específica de administrações regionais e subprefeituras, ou associações de gestão de resíduos que têm seus próprios planos de gestão de resíduos em suas áreas de responsabilidade. Estes planos incluem dados sobre o manejo de determinados resíduos, bem como sobre as instalações de tratamento destes; 
- órgão de licenciamento/autorização: em combinação com o pedido de licença/autorização, as empresas geralmente têm que apresentar documentação referente aos residuos que nela serão gerados. Esses órgãos estão em condições de fornecer dados sobre a produção de resíduos e taxas de transferência de resíduos para instalações de tratamento, por exemplo.

- outras secretarias e órgãos: por uma série de questões, outras secretarias de governo podem emitir relatórios com informações sobre resíduos sólidos, por exemplo, a Secretaria de Agricultura sobre a produção de resíduos agrícolas ou da Secretaria de Saúde sobre resíduos do serviço de saúde, etc.

- Cooperação com institutos de estatística: para um plano de gestão de resíduos, os dados estatísticos podem ser obtidos normalmente de algum órgão nacional ou regional/local e são, portanto, fácilmente encontrados nos órgãos competentes ou na internet, por exemplo, através da Pesquisa Nacional de Saneamento Básico do Instituto Brasileiro de Geografia e Estatistica (IBGE) ou do Perfil Básico dos Municipios do Instituto de Pesquisas Economicas do Ceará (IPECE), para o caso específico do estado em questão.

A informação estatística a recolher pode incluir:

- tamanho da população e suas características;

- dimensão geográfica da área a partir da qual os resíduos são recolhidos, dividido em áreas residenciais, industriais e comerciais;

- um retrato detalhado do tamanho e número de setores e atividades geradoras de resíduos (indústrias, empresas comerciais incluindo a agricultura e turismo).

Com base na vocação e na capacidade de um municipio, incluindo a economia, as políticas adotadas e metas obrigatórias a serem alcançadas, como as metas fixadas em diretivas municipais, o cenário mais realista pode ser selecionado como um ponto de partida bastante confiável para o planejamento.

Dada a dificuldade de prever a influência da parâmetros acima referidos, um certo grau de flexibilidade deve ser integrada nos cenários para assegurar que o plano escolhido possa ser adaptado por mudanças nas premissas, quantidades de resíduos, etc. Por exemplo, as variações no tamanho da população de uma determinada área podem ter uma influência significativa sobre o sistema de coleta, na capacidade do sistema de gestão de resíduos, etc. 
Portanto, a relação entre o tamanho da população e as diversas atividades do plano deve ser transparente, de modo que os ajustes necessários causados por alterações no tamanho da população possam ser feitos nas partes apropriadas do plano. Outro exemplo consiste no possível desenvolvimento de uma nova tecnologia para a reciclagem de um determinado tipo de resíduo que anteriormente era incinerado ou depositado em aterro. A influência de uma tecnologia na cadeia produtiva da reciclagem de resíduos é uma questão que deve ser identificada para avaliar se as mudanças nos sistemas atuais seriam benéficas.

Os planos de gestão de resíduos devem conter objetivos bem definidos, uma vez que estes serão concretizados em ações executadas pelo poder púbico, caso contrário, eles estarão condenados ao fracasso, como acontece com frequência. Dentre os vários compromissos presentes nos planos de resíduos sólidos, os planejadores devem atentar para o cumprimento de alguns condicionantes:

- Assumir os desafios decorrentes da Politica Nacional de Resíduos na redução sistemática dos resíduos;

- Seguir a hierarquia proposta pela PNRS para a gestão de resíduos;

- Continuar com a melhoria do sistema de coleta seletiva e reciclagem;

- Ampliar e desenvolver o apoio a cooperativas e associações de catadores de materiais reciclaveis;

- Introduzir medidas para incentivar e ampliar o número de participantes da prática de compostagem doméstica;

- Avaliar todas as políticas e práticas de gestão de resíduos em função dos critérios de proximidade, auto-suficiência regional, do principio do poluidor-pagador e desenvolvimento sustentável;

- Desenvolver sistemas de registros estatísticos, a fim de identificar tendências em produção resíduos e melhorar a tomada de decisões de sua gestão;

- Estabelecimento de programas contínuos de iniciativas de sensibilização, tanto para as empresas públicas, como privadas em geral no manejo dos resíduos sólidos;

- Trabalhar, quando possivel, em parceria com outros municipios, através de consorcios públicos e gestão regionalizada; e 
- Identificar potenciais de mercados/usos para recuperar materiais e apoiar as empresas de reprocessamento locais sempre que possível.

Os Planos são instrumentos essenciais para o correto gerenciamento e gestão integrada dos resíduos sólidos e devem garantir o controle social nas etapas de planejamento, implementação, operacionalização e fiscalização. Foram estabelecidos pela PNRS seis diferentes tipos de planejamento que devem servir de referência e ser observados de forma articulada e cooperativa entre os distintos entes federativos, sendo eles: Plano Nacional, Planos Estaduais, Planos Microrregionais e de Regiões Metropolitanas, Planos Municipais, Planos Intermunicipais e Planos de Gerenciamento de Resíduos Sólidos.

\section{OS PLANOS MUNICIPAIS DE GESTÃO DE RESÍDUOS SÓLIDOS}

É de conhecimento geral que a prática do planejamento nos municípios visa corrigir deformidades administrativas, facilitar a gestão municipal, alterar condições indesejáveis para a comunidade local, remover empecilhos institucionais e garantir a viabilização de propostas estratégicas, objetivos a serem atingidos e ações a serem trabalhadas. (REZENDE; ULTRAMARI, 2007).

O planejamento é, de fato, uma das funções clássicas da administração científica indispensável ao gestor municipal. Planejar a cidade é essencial, é o ponto de partida para uma gestão municipal efetiva diante da máquina pública, onde a qualidade do planejamento definirá os nortes para uma boa ou má gestão, com reflexos diretos no bem-estar dos munícipes (ANDRADE et al., 2005).

Um aspecto a ser considerado no planejamento municipal reside no fato de que, como passar dos anos, os problemas urbano-ambientais das cidades permanecem os mesmos e se avolumam em termos de complexidade. Cabendo ao planejador urbano conviver com essas mesmas dificuldades, agravadas, e, portanto, cada vez mais difíceis de resolver. Ao se tomar como base os planos desenvolvidos há uma década e os que ora se implementam, pode-se dizer que muitas das prioridades consideradas para um e outro permanecem as mesmas: saneamento, habitação, trânsito, ocupação de áreas ambientalmente sensíveis e deficiência de serviços comunitários. A diferença principal estaria na gravidade desses temas para o caso dos planos presentemente elaborados (REZENDE; ULTRAMARI, 2007). 
Do ponto de vista operacional, o poder público municipal configura-se como o principal executor das políticas de planejamento e gestão dos resíduos sólidos, uma vez que à União e os Estados se atribui como principal função a de normatizar, auxiliar e apoiar as ações da municipalidade (ORSI, 2006).

Partindo desse ponto, a elaboração dos planos municipais para gestão de resíduos sólidos, é condição sine qua non para que os municípios possam ter acesso aos recursos da União destinados à limpeza urbana e ao manejo de resíduos sólidos. Nesta exigência se inclui a obrigatoriedade da elaboração dos planos, pois os municípios devem definir estratégias, que busquem a redução da geração de resíduos e a sua máxima valoração, através da reutilização e reciclagem, para que apenas os rejeitos sejam encaminhados à disposição ambientalmente adequada, além do estabelecimento de metas para encerramento dos lixões (BRASIL, 2010), seguindo na esteira da prática realizada em muitos países desenvolvidos.

Os planos municipais de resíduos sólidos devem conter metas para redução, reutilização, coleta seletiva e reciclagem de resíduos, contemplando também a preocupação social para a inclusão de catadores de materiais recicláveis, trabalhadores marginalizados pela sociedade que desconhece a importância da atividade que eles realizam, propondo uma visão sistêmica da gestão de resíduos sólidos, levando em consideração as variáveis ambientais, sociais, culturais, econômicas, tecnológicas e de saúde pública.

Embora as determinações legais assim o estipulem, segundo a ABLP/SELUR (2014), em 2012 menos de 10\% dos municípios brasileiros haviam elaborado seus planos de gestão de resíduos sólidos, dentro do prazo estabelecido pela PNRS. A justificativa dos que não os haviam elaborado foi, basicamente, sempre a mesma: a falta de capacidade técnica dos gestores e de recursos financeiros, ambos dois argumentos apresentam certo grau de relatividade pois são empecilhos solucionáveis com o emprego da criatividade dos gestores e com a busca de alternativas surgidas ultimamente, como as assessorias e as consultorias ambientais que solucionam boa parte desses problemas.

Nesse sentido o Ministério do Meio Ambiente já repassou cerca de $R \$ 72$ milhões em apoio aos planos de resíduos sólidos no triênio de 2011 a 2014, montante que precisa ser melhor elucidado porque essa quantia é relativa, podendo 
ser alta, pouca ou suficiente para os objetivos propostos (ABLP/SELUR, 2014). Aqui cabe salientar um fato contraditório e que necessitaria ser equacionado: com frequência é noticiado pela mídia nacional que nem sempre o dinheiro disponibilizado pelo governo federal, os gestores locais o solicitam, havendo sempre um excedente não utilizado.

\section{CONSIDERAÇÕES FINAIS}

Os resultados indicaram que todos os 13 gestores municipais entrevistados afirmam não possuir recursos financeiros para custear a elaboração dos planos municipais de gestão de resíduos sólidos e em contrapartida 11 destes municípios não dispõem de equipes técnicas capacitadas para atender a todas as exigências do conteúdo mínimo dos planos.

Alguns municípios já possuíam planos elaborados anteriormente à aprovação da PNRS, estes terão a obrigatoriedade de elaborar novos planos ou atualizar os seus antigos agregando as exigências constantes da nova legislação sobre resíduos sólidos. Foram identificados casos em que existem planos elaborados e atualizados conforme a Política Nacional de Resíduos Sólidos, no entanto não foram implantados, caso dos municípios de Saboeiro, Jucás e Cariús, em alguns casos por limitações técnicas, em outros por falta de vontade política de seus gestores.

Embora entre os municípios da Região Centro-Sul já exista a proposta de criação de dois consórcios públicos para gestão de resíduos sólidos com implantação de dois aterros sanitários regionais, com sedes nos municípios de Iguatu e Icó, não foram identificadas iniciativas que apontassem para a elaboração de planos regionais ou intermunicipais de gestão de resíduos sólidos, fato que possibilitaria a redução de custos financeiros e a solução para a falta de capacitação dos técnicos municipais para a elaboração dos referidos planos.

Por último e não menos importante contatamos que a elaboração e implementação dos planos municipais de resíduos sólidos continua sendo um grande desafio aos gestores municipais da Região Centro-Sul do Ceará que replicase, possivelmente, também às demais regiões cearenses e brasileiras, uma vez que demandam conhecimento técnico para elaboração, implantação e implementação, além disso, o planejamento é um ação que estáfortemente relacionada ao "querer" 
de cada gestor municipal, sendo considerado o setor de resíduos sólidos uma prioridade por uma pequena minoria e um grande problema por maior parte dos gestores.

\section{REFERÊNCIAS}

ALVES, N. N. L. Caracterização de micro-bacia hidrográfica experimental no semi-árido brasileiro como suporte a estudos da degradação. Dissertação (Mestrado em Engenharia Agricola) Fortaleza: UFC, 2008.77p. Dissertação Mestrado.

ANDRADE, N. A. et al. Planejamento governamental para municípios: plano plurianual, lei de diretrizes orçamentárias e lei orçamentária anual. São Paulo: Atlas, 2005.

Associação Brasileira de Empresas de Limpeza Pública e Resíduos Especiais ABRELPE. Panorama dos Resíduos Sólidos no Brasil - 2014. São Paulo - SP: ABRELPE, 2015a. Disponível em:

http://www.abrelpe.org.br/Panorama/panorama2014.pdf. Acesso em 15 de março de 2016.

BENDELAK, M. R. Caracterização Geofísica da Folha Iguatu(Região Centro-Sul do Estado do Ceará) Integrando Dados Aerogeofísicos, Geológicos e de Imagens de Satélite. Tese (Doutorado em Geofisica) Instituto de Astronomia, Geofísica e Ciências Atmosféricas - Universidade de São Paulo- USP, 2004. Disponível em:ftp://iag.usp.br/private/adm/katia/teses/agg/d_marcelo_r_bendelak.pdf. Acesso em: 27 de março de 2016.

BRASIL. Lei no 12.305 - Institui a Política Nacional de Resíduos Sólidos; altera a Lei no 9.605, de 12 de fevereiro de 1998; e dá outras providências. 2010. Disponível em: http://www.planalto.gov.br/ccivil_03/_ato20072010/2010/lei//12305.htm. Acesso em 17 de Julho de 2012.

Gestão de Resíduos Sólidos. Brasília-DF: Ministério do Meio Ambiente, 2011.

CARNERO, R. Sistema Econômico Socialista - Socialismo Planificado.

2016Disponível em: http://moelabs.org/b37/Historia_da_Economia- 
Renato_Carneiro/I_Semestre/Aulas_em_Doc_PDF/Sistema_Economico_Planos_qui nquenais.pdf. Acesso em: 27 de junho de 2016.

GIRON, G. R. A influência da política, do planejamento e da gestão educacional na formação social do indivíduo. 2012. Disponível em:

http://www.ucs.br/etc/conferencias/index.php/anpedsul/9anpedsul/paper/viewFile/409 /109. Acesso em: 16 de abril de 2016.

HEALEY, P. Collaborative planning: shaping places in fragmented societies. London: Macmillan, 1997.

HOWARD, E. Cidades-Jardins de amanhã. São Paulo, Estudos Urbanos, Série Arte e Vida Urbana, Hucitec, 1996.

OLIVEIRA, J. A. P. Desafios do planejamento em políticas públicas: diferentes visões e práticas. RAP. Rio de Janeiro v.40, n.1. p.273-88, Mar./Abr. 2006. Disponível em: http://www.scielo.br/pdf/rap/v40n2/v40n2a06.pdf. Acesso em 05 de janeiro de 2015.

ORSI, R. A. Gestão participativa dos resíduos sólidos urbanos. Dissertação (Mestrado em Geografia), Universidade Estadual paulista, Instituto de Geociências e Ciências Exatas. 2006.

REZENDE, D. A.; ULTRAMARI, C. Plano diretor e planejamento estratégico municipal: introdução teórico-conceitual. Rev. Adm. Pública,v.41, n.2, Rio de Janeiro Mar./Apr. 2007. Disponível em:

http://www.scielo.br/scielo.php?script=sci_arttext\&pid=S0034-76122007000200005. Acesso em: 25 de dezembro de 2014.

SUSSKIND, L.; KRUIKSHANK, J. Breaking the impasse. New York: Basic Books, 1987. 